\title{
Study on Functions of Network Teaching Platform in the Education Reform of Independent Colleges
}

\author{
Ma Qinggong \\ Huaide College of Changzhou University, Changzhou, Jiangsu, China, 213016 \\ czjeepfans@163.com
}

Keywords: Network teaching platform; Independent college; Education reform; Functions

\begin{abstract}
The rapid development of information technology brings a lot of change for our daily lives. We can say that it not only changes the traditional way of work and study, making various operations simpler and quicker, but it also promotes the many changes in technology and methods, making reforms proceeded smoothly. At this point, how to properly play the role of network teaching platform in independent college education reform and how to use the network to achieve smooth and efficient operation of education reform, has became a problem must be considered for educators.
\end{abstract}

\section{Introduction}

The development of information technology and its wide application in the classroom promote the development of education reform, and make the traditional teaching mode gradually depend on network information technology and even multimedia. Now network teaching platform has become an important supplement to classroom teaching, which makes information technology applied in dynamic combination with the oral teaching and promote the further application of information technology in the teaching field. With the deepening of education reform, we must put the network platform education in an important position and make it fully play its role in promoting education reform, so as to improve the teaching efficiency and reform the teaching methods.

\section{Network Teaching Platform}

Emergence and Development of Network Teaching Platform. Network teaching platform takes the Internet as curriculum support and delivery carrier, the course content as the center, to utilize the interaction of Internet and the integration of teaching to achieve the comprehensive management of teaching and the reasonable allocation and applications of resources. So to speak, the network teaching platform has become an important part of education reform in all colleges and universities, and the reasonable application of network teaching platform not only can greatly improve the efficiency of teaching, but also can help the students to carry out the off-line study and review, so as to inspire students' self-learning awareness[1].

Network teaching platform is rising in recent years and it is produced from the combination of information technology and teaching reform. It makes up the contents of teaching links in colleges and universities, such as after-school exchange, problems solution, homework correction, teacher-student interaction, to make the curriculums more complete and substantial. The early network teaching platform has simple contents, mainly including teachers' curriculum video and lesson plans that provide support and help for the students who are absent of class or need after-school review. Subsequently, the size of network teaching platform is expanded continuously and a small number of colleges have developed the teaching information network that almost involves all universities. At this time, the teaching resources on the network teaching platform has been exchanged and developed, and students can get quick solution for their curriculum questions. Through the mutual cooperation and complementation among different network teaching platforms, the cross-disciplinary exchanges 
among different subjects is achieved gradually, and further the overall development of education reform is driven[2].

Features of Network Teaching Platform. As a teaching platform of virtualization, the content of network platform are updated and checked regularly by specially-assigned persons, to ensure the timeliness and accuracy of the platform content at any moment. Like many online platforms, network teaching platform is updated and enriched constantly for the relative teaching contents to maintain its normal operation, and to ensure its contents consistent with students' recent learning content and learning state[3]. As an important supplementary means of class teaching, the contents of network teaching platforms must be based on the class teaching, it should do well the supplement and explanation of contents and also should try to provide secondary further explanation of important and difficult teaching contents, so as to deepen students' understanding and memory.

In addition, the network teaching platform has compatibility and interaction. The knowledge on the network teaching platform is presented in various forms commonly. Besides video tutorials and courseware resources, it includes the arrangement of lesson plan contents for teachers and the initiative discussion of problems for students. In other words, the network teaching platform not only shows teaching knowledge, but also carry out exchanges between teachers and students for discussion and research. In a way, the network teaching platform is supported by the network, so it has the similar functions with the network exchange platforms of microBlog and Renren. Therefore, the network teaching platform is also a place to exchange learning experiences and discuss problems between teachers and between students. This very strong interaction changes the current status that class is lack of communication between teachers and students, expand the teaching contents and shorten the distance between students and teachers[4].

Moreover, the network teaching platform has integrative and progressive features. The integration of network teaching platform is presented by the organic integration of a variety of teaching methods and teaching contents, and the exchange and interaction between different schools and different professions. Through the arrangement of information from different sources, it makes teachers and students easily identify the most influential and targeted one, and then carry out targeted further study. The progress of the network teaching platform is relative to the traditional class teaching. Oral teaching has a long history, its content is most based on textbooks and has formed a basic mode of teaching, with little change produced. While the network teaching platform introduces a large number of excellent teaching plans and teaching modes, and teachers make continuous self-improvement and innovation on teaching methods, so the teaching methods of the platform is in continuous improvement and innovation[5]. For example, the content of the teaching platform involves after-class exchange, questions solution, exams, etc., which is emerging on the premise of continuous enrichment of this platform content and continuous expansion of teaching methods. Network teaching platform is full of innovation and progress, to ensure the existence of its vitality, and make it in a leading position in the competition of education reform

\section{The Drawbacks of Traditional Teaching Mode and the Foundation of Teaching Reform}

The Drawbacks of Traditional Teaching Mode. Independent Institutes belong to the independent secondary discipline under new mechanism, new mode and new management system, which is lack of experience in management and teaching methods, mainly copying the existing teaching mode, and this limits the relative course conduct and the curriculum reform to a certain degree.

First, the traditional teaching methods are susceptible to objective conditions, such as weather conditions, emergencies and so on. the class teaching belongs to the fixed teaching mode, with the time, place and contents prescribed, and it has strict requirements for the class staff and school hours. Students can not adjust their class time and venue according to their actual situation, so that they can 
not balance the relations between school and other activities in a sudden period of time, and thus they can not attend class normally[6].

Secondly, the traditional teaching mode is too single that hardly attract the interest of students, easily resulting students' absence of mind in class, arriving late and leaving early and even truancy etc. Single oral teaching mode takes the contents of textbooks as the starting point and the foothold of teaching, the blackboard as the main lecture platform, to achieve the progress of teaching by reading the relevant contents of textbook. It provides a cramming and mechanical teaching for large class of students, and ignores the differences in learning ability and interest of students. In addition, the unitary teaching makes the students of poor learning foundation are unable to follow up the progress of teaching, can not fully understand the contents of the class teacher taught. This causes some students gradually lose confidence for learning and reduces their motivation to learn[7].

Thirdly, the traditional teaching mode is short of exchange and rethinking after school. It overly emphasizes the utilization of class time and the mastery and understanding for teachers' lectures, but ignores the after-school review and rethinking. The absence of thinking and analysis links results in incompletion of course, adverse for students to timely consolidate and review the knowledge in class, so that the students have forgotten completely the knowledge in last class before the beginning of the next class, which has seriously affected the normal teaching schedule. Meanwhile, the traditional teaching mode has no proper evaluation system for students' study state, and it just takes the scores as the sole indicator to measure students' learning outcomes at each stage, thus affecting students' comprehensive ability to make accurate judgment[8].

The Foundation of Teaching Reform. The popularity of computer and the rapid development of Internet technology becomes the technical foundation of education reform. In simple terms, the wide application of science and technology in the field of education quickens the development of traditional education, to make schools and teachers have to constantly improve their knowledge and advance the related hardware facilities, to further make the teaching reform meet the development of times. It should be noted that the emergence and increase of high-tech talents also provides support and possibility for education reform. New-type talents have high overall quality and strong professional skill and they can fast accept new things and new ideas, so the teachers team and the leading group of them are more receptive to this reform approach to the network teaching platform, and fully promote the benefit from the reform[9].

After that, students' personalized and diverse study styles also make teaching mode changed accordingly. The new teaching mode, based on information infrastructure, begins to turn to the on-line teaching mode without limit of time and space, and gradually develop into a individualized teaching class with self-learning as the main way.

\section{The Role of the Network Teaching Platform in Teaching Reform of Independent Institutes.}

The Importance of Network Platform in Independent Colleges Teaching. In the network teaching platform for students, teachers can conduct demonstrative scene teaching and organize students for online discussions and group activities, while we can achieve real-time assessment of teaching through the relevant software of platform, realize the off-line extension of class teaching in an updated form and to establish new evaluation system of teaching.

In simple terms, the network teaching platform reduces the burden of teachers and students in class, who are freed from the boring class that has fixed time and venue, and it is convenient for them to reasonably adjust their class time and contents according to their actual situation, so as to achieve flexibility and randomness of teaching. Students can complete the information receipt through personal terminals, and can get access to and download the information related to the class content from the resource server. Teachers can mobilize the relative resources in the school library, through the comprehensive application of multimedia devices, to realize the functions of electronic lesson plans, 
electronic lesson preparation, simulation evaluation system, comprehensive evaluation system and others, so as to achieve the development of network platform of class teaching[10].

We can say that the network teaching platform makes the original teaching mode in data and information features, and it fully exerts the public and common features of teaching, to achieve the reasonable allocation of teaching resources and the resource sharing between the teachers and students to the maximum extent. At the same time, it can save various informations in the form of network data for a long period to achieve the sustainable development of teaching resource. Due to the different characteristics of independent colleges in running school and teaching methods, their network education platforms have more profound professional features. These professional features are presented not only in the on-line teaching of professional courses, but also in the professional and abundant contents of multimedia material library and test resource material library.

In addition, the network teaching platform collected and arranged by special personnel, can help the schools, teachers and students in quick and easy searching of relevant information, to reduce the waste of time caused by traditional data access methods. At the same time, it can save the relevant information in a long and safe way, to avoid the problems caused by data loss.

The Role of Network Teaching Platform in Education Reform. (1) To reform teaching mode, to achieve the informatization of teaching contents. The network teaching platform is a reform of traditional teaching methods, but also a new way of teaching by a bold attempt. The teaching mode has been changed, and then the teaching content, teaching methods and teaching objectives must be changed with the teaching mode. Simply speaking, the network teaching platform add a new situation for teaching and make teachers have to change the original way of teaching, so as to accommodate the new class in multimedia technology.

Through network teaching platform, teachers can make public their teaching goals, teaching planning, teaching content, lesson plans, to form a relatively complete and comprehensive resource system. This approach not only enriches the students' learning way, making them attend the on-line lectures and conduct after-class preview and review of the relative contents, but also improves their learning efficiency. The digital and informative network teaching resources are more open, transparent, and easy to collect, delete and get access to information, helping students repeatedly and thoroughly study the related contents and develop a sense of self-learning and active learning attitude.

(2) To enrich off-line learning mode, to increase students' interest in learning. The combination of boring specialized courses and student's favorite network platform, can stimulate students' interest in learning with the new teaching mode, guide them to learn the knowledge, and help to extend the original teaching steps to make possible the after-class discussions and exchange, the course content study, and the teacher-student interaction. The rich off-line learning mode is based on the comprehensive and powerful resource system of network teaching platform and the exchange platform[11]. Out of class, students completed the role transition from a passive attendant to an active attendant of lectures. In this case, the teaching contents on the platform can be modified and deleted, and students can adjust and choose the course content according to their own learning needs. This makes the content of online courses abundant and plentiful, and through the teaching method of repeated study and timely review, achieves layering and personalized learning approach, so that students can feel the targeted teaching programs and develop their better learning methods in combination with their actual conditions.

(3) To improve the evaluation mechanism. The student assessment and evaluation mechanism, based on attendance check and final examination, ignores the cultivation of students in comprehensive ability and the fault tolerance in case of special circumstances. While the network teaching platform is inclusive and abundant, and it achieves a comprehensive and diversified assessment mechanism. Teachers can use the system to know the students' problems discussion and group discussions, etc., and use the electronic form of raising hand to ask the students to answer questions, so as to increase the interaction in class. In addition, after the completion of teaching, teachers can also use the content 
investigation software to know the students in understanding and grasping of the content learned, so that they can make timely adjustment of the study program at the first stage.

At the mobile terminal, teachers can guide students to learn at any time, so that the students are freed from the heavy study pressure, and gradually develop their habits of active learning and positive thinking. Through the dynamic integration of lectures teaching and network teaching platform, students can better grasp of the lectures and independent colleges can improve their class efficiency.

\section{References}

[1] Zhao Honggang, Gan Yaping, Liu Shijie. Thinking on the Sustainable Development of Interactive Network Teaching Platform and its Practice [J] China Medical Education Technology, 2009 (6): 554-557.

[2] Huang Chunhong, Jie Kemin. The Development of Diversified Teaching based on Network Teaching Platform [J]. China Higher Medical Education, 2011, (11): 31-34.

[3] Yang Jianxin, Focus on Building and Improvement of the Network Teaching Platform in Schools [J] China Educational Technology and Equipment, 2008, (9): 57-58.

[4]. Yang Tieli, Chen Jun. A New Vision of Reform After-school Training[M]. Beijing Sports University Press, 2003.

[5]. Zhang Chuanfeng. Control and Application of high-level athletes training and learning time in Colleges and universities [J]. Journal of Shanghai Sports Institute, 1999, 23 (4)

[6]. Zhao Zhiheng. Learn to thinking, Master innovative learning methods [J]. Journal of Course. Teaching materials. Teaching, 1994, (1).

[7]. Li Shengwang. Status Investigation and Countermeasures of High-level Amateur Athletes's Cultural Learning of Colleges and Universities in Guangdong Province [J]. Journal of Anhui Sports Science and Technology, 2003, 24 (2).

[8]Li Wanxin. Investigation and Analysis on the Physical Exercises Condition of Nonprofessional Physical Education Students at Common Universities [J]. Western Education, 2013 (30).

[9]Liu Weifeng, Tian Jian. Investigation \& Counter-measure Research on the Physical Exercises Condition of University Graduate Students [J]. Sichuan Sports Science, 2005(3).

[10]Sun Liang. Research on Extracurricular Physical Exercises of University Students [J]. Journal of Yanbian Institute of Education, 2010(1).

[11]Dai Xingxing, Wang Bin. Research on Extracurricular Physical Exercises of University Students in Henan Province [J]. Science \& Technology Information, 2010(31). 